\title{
Sunderland Software City: The Impact of a Collaborative Project to Develop the Software Industry Within the North East of England
}

David Dunn, Alastair Irons, Peter Smith, John MacIntyre

\begin{abstract}
This paper uses a case study approach to evaluate the impact of a collaborative initiative within the North East of England which sets out to grow and sustain a software industry, based on the strengths of regional players. The project Sunderland Software City has the ambitious aim of developing the people, the infrastructure and the business and enterprise culture to create and sustain a software industry. This paper focuses upon the impact of the project, and presents some lessons learned to date.
\end{abstract}

Index Terms: Software Industry; Cluster Development; Collaboration; Business Development.

\section{Background}

\subsection{The Software Industry}

The term software cuts across standard industrial classification (SIC) codes, government department classifications and regional/local authority definitions (Chakraborty \& Jayachandran, 2001; EKOS, 2011). Within the context of this case study, the definitions used are those companies which develop software for sale as one of their revenue streams named 'primary' or 'secondary' software companies depending upon the importance of software to their income. Also included were 'latent' software companies, those who develop software for internal use.

The most prominent area in relation to software development (and the wider semi-conductor industry) is Silicon Valley. Perhaps indicative of the definition, and fluidity of software focused policy, the pinpoint start date for this exemplar area is questionable (Gromov, 2010). It was however reported to be the lack of job opportunities which drove Stanford University to undertake a series of actions to grow the electronics industry (Tajnia, 1985). The success of this industry led to the success of the intrinsically linked software industry in the area.

Manuscript submitted June $25^{\text {th }} 2013$.

Sunderland Software City is part-funded by the European Regional Development Fund, Sunderland City Council and ONE North East.

David Dunn is with Sunderland Software City, UK.

Alastair Irons, Peter Smith and John MacIntyre are with University of Sunderland, UK
Lack of high-quality jobs has also become the driver of software sector policy in other areas such as Ireland (Heeks \& Nicholson, 2002; Sands, 2005) and Iran (Nicholson \& Sahay, 2003). This raises the interesting concept of the software sector virtuous circle (see Figure 1).

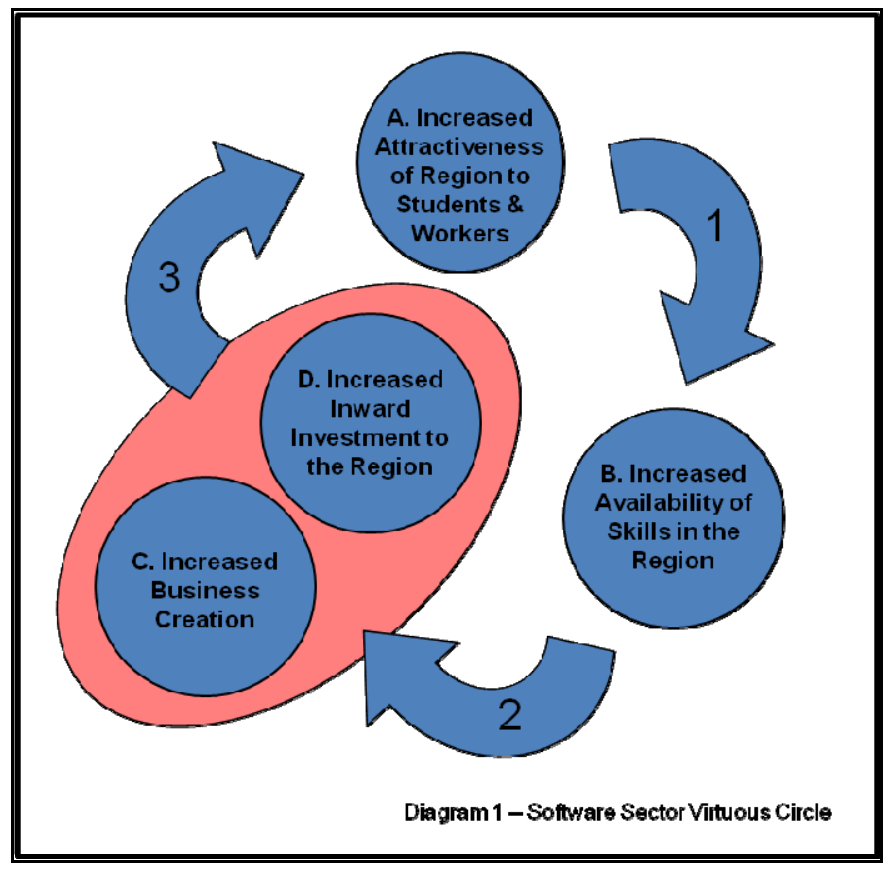

Figure 1 The Virtuous Circle

This virtuous circle can be viewed as the cause and effect of a successful software industry. Points A, B, C and D are strategic decisions, i.e. a rationales and aims made by those wishing to increase economic development. Points 1, 2 and 3 are the actions which can be undertaken in an attempt to achieve the outcomes, specifically: Activity undertaken at point 1 is all about creating a pool of talented people, whether this is through indigenous education or talent attraction; Activity at point 2 is aimed toward generating a cluster of software businesses either through business creation or inward investment; and Activity at point 3 is about place-making, i.e. ensuring the right facilities are available in order to support points 1 and 2 . 
Different locations have intercepted the circle at different points. In the examples of Silicon Valley, Ireland and Iran to reduce 'brain drain' - the driver is point ' $A$ ', to increase the attractiveness of the areas to retain (and attract new) workers. Another well documented example of a rapidly growing software industry is China. Specific government intervention continues to be used in this area (Arora \& Gambardella, 2005; Tschang \& Xue, 2005) with the drivers being points ' $C$ ' and ' $\mathrm{D}$ ', both points aimed at increasing business stock in the country (Tessler et al, 2003).

It is feasible to suggest this virtuous circle is valid for many, if not all, sectors. In the context of the software industry however it is the wider macro environment which makes the concept interesting and achievable to policy makers. Software is cross cutting and can be sold to all industries (Tessler et al, 2003), "software is the new capital" (Arora \& Gambardella, 2005), software continues to see double digit growth (Heeks \& Nicholson, 2002), software can be an agent of industrial regeneration (Romijn \& Albaladejo, 2002), software is an intermediate good (Steinmueller, 1995), the opportunities seem endless. Of equal importance to policy makers is the fact that success can be observed occurring in other geographic areas leading to the question of 'why not here?' (Carmel, 2003).

Indeed the concept of software being a weightless industry one not tied by heavy machinery or high capital costs - lends to the concept of anywhere potentially being 'the next Silicon Valley'. In the North East, and specifically Sunderland Software City, this idea is a core driver. The North East region has some historical success in growing software companies (NMP, 2007) but this is not a critical mass and is certainly not to the scale of any of the major documented successes.

\subsection{The regional and civic context}

Sunderland lies within the North East of England and traditionally has an employment rate which is below the national average. Educational attainment and aspirations are comparatively low, with a smaller proportion of residents progressing to university than the national average. The city has seen the decline of the traditional industrial base, which was based on shipbuilding and coalmining. It was within this challenging context that the Sunderland Software City programme was formed.

Within this challenging situation there were also opportunities and the foundations for the project lay in the following:

- A recognised need for change and regeneration

- Visionary leadership within the local authority, the university, small business, and the regional development agency

- A strong and established track record in Information and Communication Technology (ICT)

- A forward-thinking university with a strong research track record in Computing and a civic mission

- A local strategic partnership forged on a strong civic collaboration between the public, private and third sectors.
Sunderland was one of the first to launch a Telematics Strategy in 1996. This was a city-wide strategy which aimed to set out a vision for ICT for the future of Sunderland. This was followed by a number of initiatives such as the ENeighbourhoods Programme, Connecting the Coalfields and Sunderland Digital Challenge (Clayton et al, 2010). In Digital Challenge, Sunderland was the winner of a national competition to identify the exemplar city for the use of technology, and particularly ICT, for social inclusion. Much of the focus of ICT in Sunderland has been towards using technology to combat social exclusion. However, in recent years a number of new software businesses have grown within the city. Thus an opportunity to develop this sector was recognised.

The University of Sunderland has very firmly within its mission the concept of being a new civic university. As part of that mission it feels a responsibility to help move our city and the region forward, and become a catalyst for change. This initiative sits firmly within that context. The University also has a long and strong tradition of research and education in Computer Science, and this was recognised as a key foundation for this project. The research which underpins the Sunderland Software City covered several aspects of software development (Edwards \& Mallalieu, 1999; McDonald \& Edwards, 2007; Moses et al, 2002; Oatley et al, 2002; Zhong et al, 1999) and was situated in a number of research centres as discussed in Hall et al (2010). There is a strong ethos of partnership within the city and the region. All of the major players recognise the strength and power which can be gained from working together. This initiative is a direct result of this strong belief in collaborative working.

It was from all of the above that the Sunderland Software City project was formed. All were necessary and fundamental to forming the project. This paper seeks to discuss the impact of the project to date, and to explore the model of knowledge exchange on which it is based. The project focuses on enterprise and entrepreneurship in the software development sector, and serves as an example of how a university and its city and region can work together to drive change and make significant economic impact.

\section{Project Overview}

Coming from the context explained above, Sunderland Software City was formally established in November 2008 with the main objective of enhancing the software development industry in the North East of England. The project was funded by the North East Regional Development Association (ONE North East) and the European Union (through the European Regional Development Fund). The aim of the Sunderland Software City project is to create:

- $\quad$ an established, innovative and sustainable software industry in Sunderland and the North East of England

- $\quad$ a high calibre workforce to support the needs of a regional software industry 
- $\quad$ an education sector encompassing secondary, further and higher education which provides technical and business education and training

- an environment which develops and supports inspirational students and workers in the software industry throughout their careers

- an infrastructure providing world-class business accommodation and communications connectivity

The project thus seeks to create a virtuous circle which: develops a pool of skilled people; encourages the creation of new businesses and the expansion of existing business; and makes the North East a focal point for software development. These elements are closely entwined and dependent on each other, in that success in one element promulgates success in the others, thus forming an ongoing upward spiral. Sunderland Software City is an initiative to transform the North East into a compelling location of choice for software companies, whether they are start-up, already established of moving in from overseas.

Sunderland Software City has a strategy to 2020: “By 2020 the North East will be home to 2,200 software companies who will employ over 15,000 and contribute nearly E1.1bn to the regional economy. This growth will be underpinned by regionally created intellectual property, driven by increased $R \& D$ spend and the availability of a highly skilled, trained workforce.". The business model is based on a partnership approach (see Figure 2), involving a small core team working alongside Sunderland City Council, Sunderland University, and the North East Business and Innovation Centre.

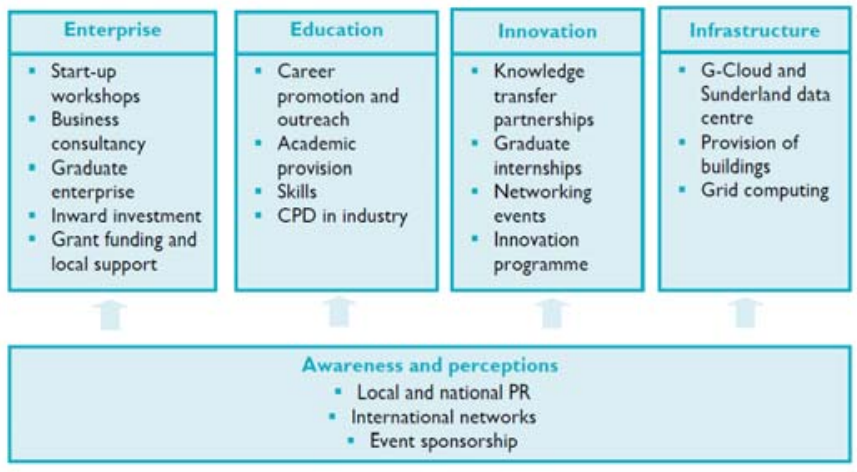

Figure 2 Sunderland Software City delivery structure

The project uses a novel model of knowledge exchange as shown in Figure 3, which builds on the strengths of the local partnership including the research strengths of the local university (Hall et al, 2010).

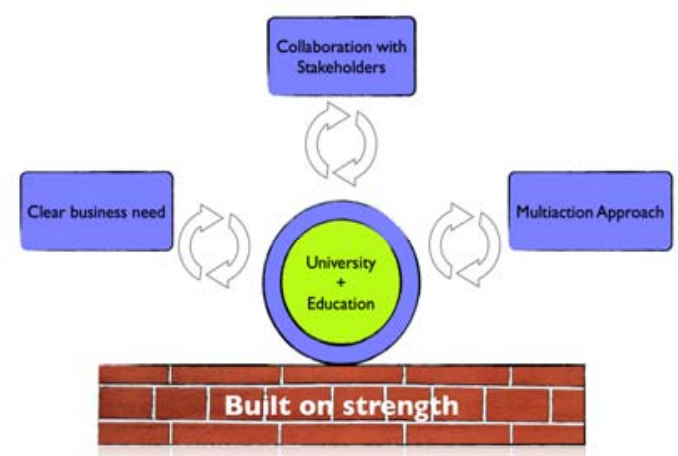

Figure 3 Knowledge Exchange Model (Hall et al, 2010)

Sunderland Software City secured ERDF funding to support the delivery of these activities through two separate, but interlinked projects. The 'Sunderland Software Centre' project secured $£ 4.7 \mathrm{~m}$ of ERDF, matched with $£ 2.9 \mathrm{~m}$ of Single Programme funding and $£ 2.6 \mathrm{~m}$ from Sunderland City Council, to create a new, specialist accommodation centre and growth hub for software businesses located in Sunderland City Centre. The Centre opened in late 2012. The 'Sunderland Software City Phase 2' project secured $£ 1.86 \mathrm{~m}$ of ERDF funding, matched against $£ 1.86 \mathrm{~m}$ from Sunderland City Council, to deliver a range of services and activities to support the growth of the regional software sector.

\section{Evaluation of Impact \\ 3.1 Methodology}

The Sunderland Software City project has now been operating for almost five years, and it was considered that this was an appropriate time to evaluate the impact of the project on the city. The methodology used for the evaluation of impact is a case study approach (Yin, 2012). The sector has also benefited from several previous case studies (Nicholson \& Sahay, 2003; Trauth, 2000; Wang, 1996; Paija, 2001). Analysis of the case study has been done via a mixed method approach including quantitative measure of impact (EKOS, 2011); and analysis of three software companies, each with a different form of intervention.

\subsection{Quantitative measures}

The Software City project has recently been evaluated (EKOS, 2011). The material in this section is taken from that evaluation. It is estimated that, in 2009, there were 132 software businesses in Sunderland and 1,385 in the North East. The sector accounted for $3 \%$ of all businesses in Sunderland and $2.5 \%$ of all businesses in the North East, compared with $3.7 \%$ for the whole of the UK (excluding London) (see Figure 4). 


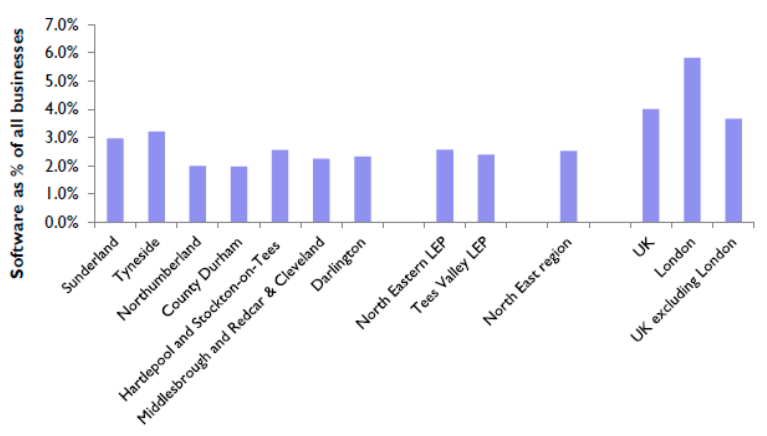

\section{Figure 4 Software businesses as \% of all businesses (EKOS, 2011)}

As part of the baseline research, a survey of North East software businesses was undertaken to help understand the characteristics and needs of companies in the sector. Data on the characteristics of 37 businesses was gathered through the survey. While this is a small sample, and certainly not representative of the software sector as a whole, the results provide some useful information about the characteristics of this snapshot of software companies.

The majority of businesses responding to the survey are relatively small, with $65 \%$ employing less than 10 staff, of which $43 \%$ have between one and four employees. The small average company size is also reflected by the data on turnover which shows that $68 \%$ of businesses have an annual turnover of less than $£ 0.5 \mathrm{~m}$, of which $38 \%$ turnover less than $£ 100,000$ p.a. $16 \%$ of the businesses responding are sole traders or partnerships. There are some larger businesses in the sample, with $11 \%$ employing between 50 and 99 staff and $5 \%$ with a turnover of more than $£ 10 \mathrm{~m}$ p.a. However, the sample is largely dominated by small and micro businesses. The majority of survey respondents (46\%) are based in Tyneside, with 22\% located in Sunderland, highlighting the relative concentration of North East software businesses in Newcastle and the wider Tyneside conurbation.

$89 \%$ of survey respondents have their ownership and headquarters in the North East, with $27 \%$ headquartered in Sunderland and $62 \%$ in other parts of the region. Only $11 \%$ are owned by parent companies elsewhere in the UK (e.g. West Sussex and Bedford) and had invested in establishing a business operation in the North East. None of the businesses responding were owned by overseas companies.

The majority of businesses (52\%) are involved in software development activities and supply a variety of industry sectors, from transport and distribution to the financial and sales sectors. The next largest area of activity is the 'business support' category which accounts for $24 \%$ of respondents, and includes work such as marketing, training, IT support and $\mathrm{PR} /$ media relations. A smaller number of businesses are involved in website design activities such as videography, online fitness and media, and e-commerce design.
91\% of businesses responding describe themselves as established, while only $9 \%$ are either recent start-ups or have been trading for less than one year.

For most respondents, the majority of their business is with customers in other parts of the UK and / or the North East. More than one third of businesses generate over $50 \%$ of their income from customers in the North East, and almost half of all businesses earn more than $50 \%$ of their turnover from customers in other parts of the UK. More than half of the businesses responding recorded no sales at all to Europe or other overseas markets.

The total annual turnover of the software industry is estimated in 2008 at approximately $£ 38 \mathrm{~m}$ in Sunderland, $£ 589 \mathrm{~m}$ in the North East and £52,215m in the UK (or £36,725m in the UK excluding London). For the North East as a whole, average turnover per software employee was $£ 60,000$ and GVA per software employee was $£ 41,000$. The ratios in Sunderland were £48,000 turnover per employee and £32,000 GVA per employee. Turnover and GVA per head are higher on average in the UK (excluding London), at $£ 106,000$ and $£ 58,000$ respectively.

While the early stages of the recession in 2008 and 2009 appear to have impeded the progress of the software sector, it seems to have remained resilient and does not appear to have taken a major step backwards during this time. Overall, the sector in the North East could be considered to be still in its early stages and emerging when compared with software centres in other regions of the UK.

A key aim of Sunderland Software City is to encourage more people, especially young people, to study ICT and software related subjects and to supply the higher level skills needed to help the industry grow. There are some encouraging signs that the education system is helping to meet this challenge. For instance, the number of young people under 19 years old starting ICT education programmes in the North East increased by $15 \%$ between $2008 / 09$ and 2010/11, and by $29 \%$ in Sunderland. In 2009/10, 4.8\% of all enrolments with HE institutions in the North East were students on a Computer Science course, compared to the average for England of $4 \%$. It is clear that graduates are an important source of skills for North East software businesses, with around half having more than $70 \%$ of the workforce accounted for by graduates. However, there is also an important role for non-graduates in the industry. For one quarter of businesses, between $21 \%$ and $50 \%$ of the workforce are non-graduates.

Most areas of the North East experienced a decline in the number of software enterprises between 2008 and 2009. However, Sunderland, Northumberland and County Durham showed net increases although the actual number of businesses involved was small. The overall pattern is that the number of software businesses in the North East declined at a lower rate between 2008 and 2010 (2\%) than the average for the UK (6\%) (see Figure 5). 


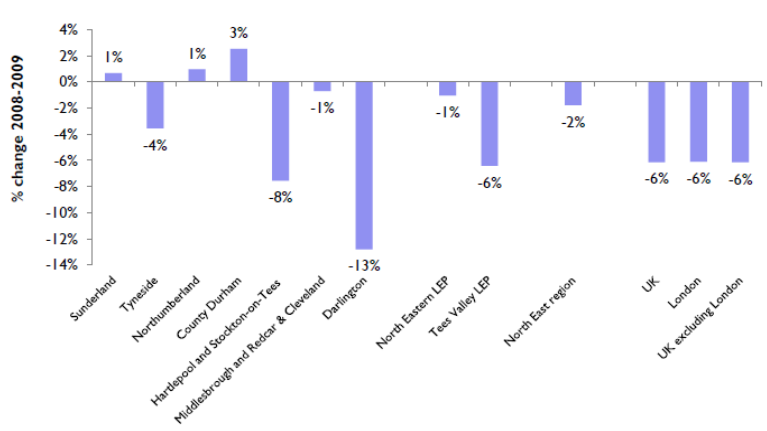

Figure 5: Change in number of software enterprises (2008 to 2009) (EKOS,2011)

3.3 Software Company A: Use of a KTP (Knowledge Transfer Partnership) as a development tool

Established in 1994, Company A is one of the UK's leading software development houses. Company operations focus on the production and development of a market-leading product for a diverse range of clients. The software community is moving increasingly towards adopting the Microsoft .NET platform, and associated development methodologies, as a standard for future development initiatives: it was, therefore, essential that Company A took this opportunity to align its future development policy to the stated platform and practices. This was not only a strategic requirement, in line with innovations in intranet development, but also a required response; the potential for future development using the existing platform's technologies was somewhat restricted, requiring a definite shift in strategic direction that was best achieved by incorporating the high-level knowledge transfer and development methodologies afforded by .NET both into its products and its staff knowledge base.

The aim of this two year KTP, was to embed these skills within Company A in order that they can fully exploit the capabilities of the .NET platform into future versions of their product platform. Benefits to the local university were in providing student study materials based on technical aspects of the project, and greater insight into project management techniques and issues within a software company, with regard to web development projects. Innovative cloud-based technology, developed in partnership with the university, helped Company A expand its business into global markets, increase its competitiveness, profitability and clients, as well as foster an open innovation environment among its own team.

The company said of the intervention: "In order to create this new product for a global mass market we were required to take an entirely different focus; The new product was created using technology that is suitable for our current market, and although it allowed us to create a great product, the new technology will be more suited to a move to the cloud. We have extensive knowledge in the technologies we've been using for the past 12 years; however, we had a clear knowledge requirement when it came to modern development methodologies and technologies. The KTP has helped us meet that requirement, arming us with the skills and knowledge required to move our development strategy forward. The KTP also helped us work more efficiently as a development team."

The Associate working on the KTP, said: "The KTP project has given me a fantastic opportunity to work for a leading UK company such as Company A; the partnership arrangement has placed me in a position where I can really contribute to the team and help to drive our product forward, and it has given me the skills to communicate effectively with the team here, enabling me to present my own ideas and highlight opportunities to improve our product even further."

\subsection{Software Company B: Inward investment}

Company $\mathrm{B}$ is a cloud computing specialist delivering wireless connectivity and computing solutions which reduce customer's expenses, ensure business continuity and strengthen data security. Originating in another area of the UK, Company B consulted Sunderland Software City when looking to open their first office in the North East.

Sunderland Software City provided Company B with a detailed business intelligence report analysis on: North East IT sector competitor analysis, including company size, location and turnover; Information on the top 300 companies in the North East and Key sector analysis. This information provided a thorough and in-depth analysis of the North East's businesses community, helping Company B to better plan and prepare for a move into the region.

Following advice and support in moving to the region, the company moved into offices in the North East in August 2012. Sunderland Software City then helped in the recruitment and training of four members of staff to work out of the company's North East office full time.

\subsection{Software Company C: The use of consultancy and business support}

Company C invests in technology ideas working with technology entrepreneurs and start-ups to help grow their business and get to market fast, providing marketing resource and access to international connections to get their business running. In addition to providing services to entrepreneurs and start-ups, Company $\mathrm{C}$ also run a company dedicated to designing and building its own app products and services. The company has many projects in development and a growing development team to support this work.

Sunderland Software City has been providing support and advice to Company $\mathrm{C}$ since its inception, helping in the initial stages to help the company director to identify and recruit staff with the right entrepreneurial and creative flair needed to get the company's initial projects off the ground. Sunderland Software City has supported the creation of 13 jobs in total at Company C. Company $\mathrm{C}$ has also recently provided access to user testing facilities at the University of Sunderland to aid the development an app product.

\section{Discussion and Conclusions}


Overall, the software industry in the North East is developing and making progress, despite the challenges presented by the recent recession. Much of this is due to the impact of the Sunderland Software City project. Changes in the sector appear to be gradual and organic, rather than dramatic, although it does appear that the project interventions are providing a sound platform for further growth. The sector has made good progress in recent years and offers strong prospects for future growth. Due to rapid advances in technology, the sector appears to be able to grow turnover relatively quickly. The software sector can thus be seen as an important contributor to wealth generation in the North East.

The project has provided a very strong infrastructure for software businesses wishing to locate and grow in the region, which is now very well placed in terms of software and ICT infrastructure, and this will be a key enabler of sector growth in the future. The partnership working of the public sector, the private sector and the local university is vital to the success of the project. The success of the project to date has, in part, resulted from the use of a breadth of different intervention mechanisms, as demonstrated in the case studies above.

It is right to be ambitious and optimistic about the future growth prospects for the software industry in the North East and Sunderland. The region is home to many innovative businesses which, given the right conditions, will undoubtedly grow. At the same time, it is important to be realistic about the growth potential of the sector and to work towards a vision and targets that are stretching but achievable. The impact of the project is considerable, and will continue to be felt in the future.

The project has demonstrated the importance of collaboration and partnership working, as depicted in Figures 2 and 3. Figure 3 proposed a model which was built on academic strength, a clear business need, a multi-action approach and collaboration with stakeholders. We believe that this initial evaluative analysis provides validation of that model. We will continue to evaluate the success of the project in the future.

\section{ACKNOWLEDGMENTS}

Sunderland Software City is part-funded by the European Regional Development Fund, Sunderland City Council and ONE North East. The authors wish to acknowledge the support of those organisations.

The authors wish to acknowledge ECOS who provided the evaluation of the project.

\section{REFERENCES}

[1] Carmel, E., (2003). The New Software Exporting Nations: Success Factors. The Electronic Journal of Information Systems in Developing Countries, 13(4), pp.1-12. Available from www.ejisdc.org [accessed 1 March 11].
[2] Clayton, J., Macdonald, S. J. \& Wilcock, A. (2010). City of Sunderland Digital Inclusion Evaluation Final Report. Working Paper Department of Social Sciences, University of Sunderland.

[3] Edwards, H. M., \& Mallalieu, G. M. (1999). RAMESES: A method for evaluating change in small organisations. In Software, IEE Proceedings- (Vol. 146, No. 3, pp. 137-144). IET.

[4] EKOS, (2011). Sunderland Software City - Final Evaluation. March 2011.

[5] Gromov, G., (2010). Silicon Valley History. Online article available from http://www.netvalley.com/svhistory.html [accessed 26 April 2011].

[6] Hall, L., Irons, A., MacIntyre, J., Sellers, C., \& Smith, P. (2010). Sunderland Software City: an innovative approach to knowledge exchange in the North East of England. Research in Post-Compulsory Education, 15(3), 317-327.

[7] Heeks, R. \& Nicholson, B., (2002). Software export success factor sand strategies in developing and transitional economies. Development Informatics Working Paper Series, Working Paper No. $12 . \quad$ Available from http://www.sed.manchester.ac.uk/idpm/research/publications/wp/di /di_wp12.htm [accessed 8 March 2011].

[8] McDonald, S., \& Edwards, H. M. (2007). Who should test whom?. Communications of the ACM, 50(1), 66-71.

[9] Moses, J., Farrow, M., \& Smith, P. (2002). Statistical methods for predicting and improving cohesion using information flow: an empirical study. Software Quality Journal, 10(1), 11-46.

[10] Nicholson, B. \& Sahay, S., (2003). Building Iran's Software Industry: An Assessment of Plans and Prospects. The Electronic Journal of Information Systems in Developing Countries, 13(66), pp.1-19. Available from www.ejisdc.org [accessed 1 March 11].

[11] Oatley G, MacIntyre J, Ewart B, Mugambi E, (2002). SMART software for decision makers KDD experience, Knowledge-Based Systems, 15(5-6), July 2002, Pages 323-333

[12] Paija, L., (2001). What is behind the Finnish 'ICT Miracle.' ETLA. Available from http://www.etla.fi/files/932 FES 01 3 ict miracle.pdf [accessed 28 June 2012] Economy

[13] Sands, A., (2005). The Irish Software Industry. In: Arora, A. \& Gambardella, A. eds., (2005). From Underdogs to Tigers. The rise and growth of the software industry in Brazil, China, India, Ireland, and Israel. Oxford: Oxford University Press.

[14] Steinmueller, W.E., (1995). The U.S. Software industry: An Analysis and Interpretive History. Prepared for the University of California, Berkeley, International Computer Software Industry Project. Available from: http://citeseerx.ist.psu.edu/viewdoc/summary?doi=10.1.1.104.186 [accessed 9 March 2011].

[15] Tajnai, C.E., (1985). Fred Terman, the Father of Silicon Valley. Design \& Test of Computers, IEEE, 2(2), p.75-81

[16] Tessler, S., Barr, A. \& Hanna, N., (2003). National Software Industry Development: Considerations for Government Planners. The Electronic Journal on Information Systems in Developing Countries, 13(10), pp.1-17. Available from: www.ejisdc.org [accessed 1 March 11].

[17] Trauth, E.M., (2001). Qualitative Research in IS: Issues and Trends. Hershey, PA: Idea Group Publishing. 
[18] Tschang, T. \& Xue, L., (2005). The Chinese Software Industry. In: Arora, A. \& Gambardella, A. eds., (2005). From Underdogs to Tigers. The rise and growth of the software industry in Brazil, China, India, Ireland, and Israel. Oxford: Oxford University Press.

[19] Wang, V. W., (1996). Developing the Information Industry in Taiwan: Entrepreneurial State, Guerrilla Capitalists, and Accommodative Technologists. Pacific Affairs, 68(4), pp.551-576.

[20] Yin, R.K., (2012). Applications of Case Study Research. $3^{\text {rd }}$ Ed. Thousand Oaks, CA: Sage Publications.

[21] Zhong, B., MacIntyre, J., He, Y., \& Tait, J. (1999). High order neural networks for simultaneous diagnosis of multiple faults in rotating machines. Neural Computing \& Applications, 8(3), 189195.

\section{ABOUT THE Authors}

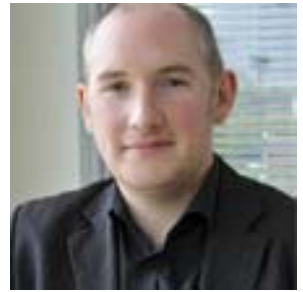

David Dunn is Chief Executive Officer of Sunderland Software City. David's responsibilities include the strategic coordination of the client facing services; new project development, including working with end users to design and procure innovative products and services; and developing and executing inward investment strategies. Before moving to Sunderland Software City, David spent over three years in a variety of senior executive roles within the regional development agency One North East including as manager for the development and delivery of service sector projects, including the digital, design, Knowledge Intensive Business (KIB) and commercial creative sub-sectors. His previous post involved shaping strategies and action plans for these specific sub-sectors.

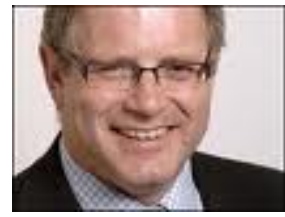

Dr Alastair Irons is Head of Department for Computing, Engineering and Technology at the University of Sunderland. His research interests focus on computer forensics and pedagogic issues in higher education with particular interest in student assessment and feedback. Alastair is a National Teaching Fellow, a Fellow of the BCS, a Fellow of the IET, a Fellow of the HE Academy and Senior Fellow of SEDA. Alastair is Chair of the Sunderland Software City Operations Group at the University. External to the University Alastair is vice chair of the BCS Academic Accreditation Committee and serves on the Board of the North East Fraud Forum.

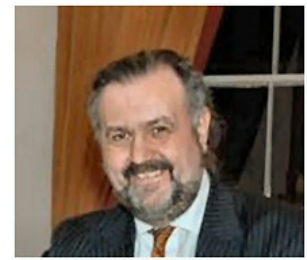

Professor Peter Smith is Emeritus Professor of Computing at the University of Sunderland. He has published over 250 papers, and spoken at conferences throughout the world. Peter has supervised, and examined over 100 doctoral candidates, and is a Fellow of the British Computer Society, a Chartered Engineer and a Fellow of the Higher Education Academy. He has recently co-authored a text book for Professional Doctorate students, published by Palgrave.

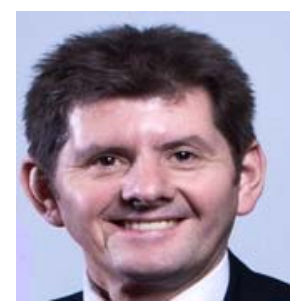

Professor John MacIntyre is Dean of the Faculty of Applied Sciences and Pro Vice Chancellor at the University of Sunderland. He has a brief covering Research, Innovation, Knowledge Exchange, Employer Engagement and Regional Economy. John led the work with colleagues to develop and implement the University's Research Plan, setting out a vision and strategy for research across the University to 2020. His personal areas of expertise and research_are in artificial intelligence, predictive maintenance, bioinformatics, and business and organisational change. He has published over 140 papers including invited contributions to international journals and conferences. He is Editor-in-Chief of Neural Computing \& Applications, an international scientific peer reviewed journal published by Springer Verlag. 